www.pasosonline.org

\title{
Turismo, pueblos indígenas y patrimonio cultural en México y Chile
}

\author{
Cristina Oehmichen Bazan* \\ Universidad Nacional Autónoma de México (México) \\ Francisca de la Maza Cabrera** \\ Pontificia Universidad Católica de Chile (Chile)
}

\begin{abstract}
Resumen: En este artículo se explora la incorporación de los pueblos indígena a los procesos de patrimonialización y turistificación en México y Chile. Ambos países tuvieron un desarrollo histórico diferente, incluso opuesto, con respecto a su relación con sus pueblos originarios. No obstante, en los últimos años han coincidido en llevar a cabo políticas públicas de reconocimiento de ciertos derechos a la diversidad cultural. El uso cada vez más frecuente de las tradiciones, ceremonias, danzas, música y otras expresiones culturales indígenas por parte de la industria del turismo, contrasta con la falta de reconocimiento a sus derechos colectivos sobre sus territorios. La turistificación de las regiones indígenas es un ejemplo conspicuo que muestra la manera en que el multiculturalismo neoliberal en América Latina incorpora a los pueblos indígenas bajo ciertas premisas y condiciones, a la vez que los excluye bajo otras premisas y condiciones.
\end{abstract}

Palabras Clave: Pueblos indígenas; Turismo; Identidades étnicas; Patrimonio.

\section{Tourism, indigenous peoples and cultural heritage in Mexico and Chile}

Abstract: This article explores the incorporation of indigenous peoples into the heritage and tourism processes in Mexico and Chile. Both countries have had different historical developments, that could even be considered diametrically opposed to one another, with respect to their native peoples. However, in recent years both have coincided in developing State policies for the recognition of certain rights to cultural diversity. The increasingly frequent use of traditions, ceremonies, dances, music and other indigenous cultural expressions by the tourism industry,contrasts with the lack of recognition of the native peoples' collective rights over their territories. The touristization of the indigenous regions is a conspicuous example of how neoliberal multi-culturalism in Latin America incorporates indigenous peoples using specific premises and conditions at the same time as it excludes them by using other equally specific, protocols.

Keywords: Indigenous people; Tourism; Ethnic identities; Heritage.

\section{Introducción}

Históricamente, los pueblos originarios de América Latina se han visto involucrados en el desarrollo del turismo, ya sea porque sus tierras, recursos naturales y territorios han sido afectados por el avance del capital turístico e inmobiliario, sea porque sus miembros se emplean en diversas labores relacionadas con la expansión turística, o bien, porque ellos ven en el turismo una vía para acceder a recursos a través de la venta de productos y servicios, entre otras razones. No obstante, en las últimas dos décadas, la diversidad cultural que encarnan en tanto colectividades culturales diferenciadas, con lenguas, tradiciones, costumbres, artes, visión del mundo y formas de organización social propias, ha venido a ocupar un papel destacado en la promoción turística.

\footnotetext{
Doctora en Antropologia por la UNAM - Universidad Nacional Autónoma de México. Instituto de Investigaciones Antropológicas; E-mail: cristina.oehmichen@gmail.com

**Doctora en Antropología por el CIESAS - México; E-mail: fcadelamaza@uc.cl
} 
La contribución del turismo a la generación de divisas y al producto interno bruto (PIB) en una gran diversidad de países, ha traído consigo el crecimiento del sector, con una fuerte competencia entre destinos y ofertas. En este contexto, la identidad étnica de los pueblos indígenas -reconstruida y reconfigurada con fines de promoción turística- ha adquirido una gran importancia.

La distintividad étnica y cultural como eje de atracción turística es un fenómeno relativamente reciente y poco estudiado. Su desarrollo se ubica dentro de un universo semántico que hace referencia a la otredad y que permite construir metalenguajes que aluden a la ancestralidad (cualquiera que sea el significado que se le otorgue) y a la autenticidad, dos valores claves en el proceso de patrimonialización de la cultura, (Heinich, 2015). La diversidad étnica ofrece a los turistas la posibilidad de tener una experiencia de vida que enriquece su capital cultural y les permite mantener un dialogo con miembros de otras culturas.

En este contexto, los pueblos indígenas aparecen representados ante la "mirada del turista" (Urry 2002), como sociedades tradicionales y premodernas, apegadas a una naturaleza prístina y distante del consumo urbano metropolitano. En ese dialogo con la otredad, también son vistos como una alternativa civilizatoria que muestra que otro mundo "donde quepan muchos mundos" es posible, como ocurrió con el alzamiento de los zapatistas en enero de 1994, cuya identidad y aceptación por parte de diversos grupos de la sociedad global, incluye a los turistas. La diversidad cultural que encarnan los pueblos indígenas adquiere diversos significados, dependiendo de los actores y contextos específicos de interacción.

En este artículo se explora la relación entre turismo, patrimonio y pueblos indígenas a través de la experiencia de dos países: México y Chile. Partimos de considerar que la incorporación de las expresiones culturales indígenas al proceso de construcción de la identidad nacional, no está separada de la visión que se promueve a través de la moderna industria del turismo y de las políticas de patrimonialización de sus culturas. El uso cada vez más frecuente de las tradiciones, ceremonias, danzas, música y otras expresiones indígenas por el turismo, contrasta con la falta de reconocimiento a sus derechos colectivos.

\section{Perspectiva teórica y metodológica}

En las últimas dos décadas, los pueblos indígenas han estado involucrados en el proceso de turistificación en tanto colectividades culturales con tradiciones "ancestrales", algunas de las cuales forman parte del "patrimonio cultural de la humanidad" reconocido por la UNESCO. El reconocimiento de sus prácticas culturales como "patrimonio intangible", favorece los imaginarios que ubican a los pueblos indígenas como premodernas, cuyas prácticas están dotadas de un aura de ancestralidad que los distingue de la cultura moderna y cosmopolita, en función de una "economía de la autenticidad" (Heinich 2015).

El reconocimiento que la UNESCO hace a determinados tipos de prácticas culturales, confluye con el desarrollo del turismo y contribuye a resignificar la identidad étnica e indígena. En el contexto turístico, la identidad indígena se reconstruye para significar y difundir aspectos de la cultura de un pueblo o una sociedad (como sus danzas, su producción artesanal, su gastronomía y aspectos de su cosmovisión), a expensas de otros aspectos que tienden a ocultarse (como podrían ser las condiciones de explotación de los artesanos indígenas) o a silenciarse (como las demandas políticas de reconocimiento a sus derechos colectivos). No obstante, el escaparate turístico bien puede ser una tribuna utilizada por las propias organizaciones indígenas para difundir sus demandas, como ha ocurrido con el movimiento zapatista en Chiapas (Coronado 2008).

Los pueblos y comunidades indígenas participan del turismo a través de la venta de sus productos artesanales, su música, sus danzas (Flores y Nava, 2016), sus ceremonias (Zúñiga, 2016), o productos de la cocina regional. También ofrecen sus textiles y atuendos que entran al mercado como "moda étnica contemporánea", que en varios casos ha significado la apropiación o el despojo de sus creaciones por parte de grupos ajenos a sus comunidades, que aprovechan del vacío jurídico para negar el reconocimiento y el justo pago a los creadores. Finalmente, los miembros de los pueblos originarios participan como trabajadores con o sin salario en las ciudades y emprendimientos turísticos, en las cadenas hoteleras, en los restaurantes, tiendas, boutiques o en la industria de la construcción, entre otras muchas actividades laborales que con frecuencia se encuentran estratificadas y racializadas.

La industria turística tiene la capacidad de reinventar y producir "lugares" (López y Marín, 2010), esto es, espacios valorizados por sus atractivos turísticos: selvas, desiertos o bosques. Pero además, en dichos lugares la presencia indígena transfiere a los territorios turistificados su identidad. Por ejemplo, en México, se habla del "Mundo Maya", como en Sudamérica se habla del mundo andino. 
Los significados de lo indígena se asocian con la noción de "lo auténtico", entendiendo por ello lo profundamente arraigado, lo vinculado con el origen o con la autoctonía (Frigolé, 2014). Lo "auténtico" permite al Estado, a las instituciones internacionales, a las grandes cadenas de tour operadores y a otros actores sociales promover "...el descubrimiento y creación de nuevos tipos de riqueza" (Frigolé ibid: 38), a partir de su puesta en valor por el mercado de bienes simbólicos articulados por el turismo.

México es uno de los países donde las culturas indígenas y sus territorios respectivos se han constituido en importantes espacios turísticos asociados a una industria de proyección internacional. Este mismo fenómeno, con menor intensidad, se puede observar en el norte de Chile, en San Pedro de Atacama, uno de los principales atractivos turísticos del país, donde el paisaje del desierto y la cultura ancestral andina forma parte esencial de su oferta e identidad turística (de la Maza, 2017).

La turistificación de las regiones indígenas es un ejemplo conspicuo de un multiculturalismo neoliberal (Hale, 2002) que en América Latina tiende a incorporar a los pueblos indígenas bajo ciertas premisas y condiciones - por ejemplo, como músicos, creadores de arte, portadores de tradiciones atractivas a la mirada del turista- a la vez que, bajo otras premisas y condiciones, se les excluye, como cuando se les niega su reconocimiento jurídico como sujetos colectivos con derecho a su cultura, al territorio y formas de organización social. Sin embargo, su incorporación a estos procesos de turistificación como agentes que emprenden economías turísticas comunitarias también les ha permitido, en algunos casos, ser activos defensores de su cultura y territorio, generando procesos de revitalización cultural y creando nuevas oportunidades económicas en un plan de reconocimiento a su cultura.

El estudio sobre la relación entre el turismo y los pueblos indígenas ha avanzado, a pesar de las dificultades iniciales de posicionar el tema. Esto es así porque los pueblos indígenas se han relacionado con el turismo de múltiples formas, a veces como meros objetos y otras como sujetos activos. Este es el caso del turismo indígena, que tiene sus particularidades. Se ha dicho que éste nace como respuesta al turismo de masas, indiferenciado y homogéneo. Al turismo indígena se le ha relacionado con diversos tipos de turismo como el etnoturismo, turismo cultural, turismo comunitario, turismo rural, ecoturismo, o turismo alternativo, cuya particularidad es el interés de los visitantes de conocer rasgos específicos de una zona y cultura indígena.

El turismo indígena se ha definido con diferentes énfasis. Siguiendo a Grünewald (2006) y Pereiro (2015) es entendido como un tipo de turismo que implica explícitamente la presencia de comunidades o personas indígenas, a través de su control o porque su cultura es la esencia del atractivo, a diferencia del turismo étnico que no contempla necesariamente grupos indígenas, pero sobre todo, debe entenderse como "un modo de hacer" turismo, donde los indígenas son agentes centrales de los emprendimientos.

Pereiro (2015) destaca la relación entre el turismo indígena y la etnicidad, pues esta se reconstruye para los turistas, para la visión y el consumo mercantil de la cultura indígena. A través del turismo se transfieren las identidades y los lugares indígenas al mercado turístico global. Ello puede derivar en dominación, explotación, subordinación, resistencia, reinvención, preservación y recreación de atributos étnicos, y suele producirse a costa de perder privacidad y causar un cierto sentimiento de invasión y amenaza (Comaroff y Comaroff 2011). No obstante, el turismo indígena también puede generar nuevas condiciones económicas y de control territorial que quizás serían impensables sin la llegada del turismo.

El análisis del turismo en territorios indígenas abre la discusión sobre las políticas de reconocimiento o multiculturales. Esto implica analizar el desarrollo del turismo en el contexto del multiculturalismo neoliberal o dentro de un marco de políticas neoliberales que incorporan el reconocimiento de los derechos indígenas. Sin duda, cada país latinoamericano tiene variedades respecto a las formas en que esto se materializa en acciones concretas desde el Estado, el sistema económico y las formas de contención de los pueblos indígenas. En este artículo, comparamos dos países con historias diferentes respecto a su construcción nacional para aportar a este debate más amplio.

Respecto a la metodología, este artículo forma parte de dos investigaciones que se realizan en México y Chile sobre los procesos de turistificación de los territorios indígenas y sus implicancias respecto a las políticas de reconocimiento, los derechos de los pueblos indígenas, los procesos de marginación y explotación laboral indígena en contextos de turismo de masas y el uso de la cultura indígena como un valor turístico, entre los temas centrales. Las investigaciones se realizan desde una perspectiva principalmente etnográfica, que busca contrastar diferentes casos de estudios con procesos regionales y nacionales que permitan dar cuenta de la complejidad de los procesos turísticos y su relación con los pueblos indígenas. Considerando estos dos procesos investigativos, este artículo toma alguno de estos elementos con un enfoque comparativo a nivel países, seleccionando algunos ejes de análisis que permitan ver contrastes y similitudes. 


\section{Patrimonio cultural y turismo: el caso de México}

En México, la construcción cultural de la nación partió del reconocimiento de una épica, una historia y una narrativa que recupera la grandeza de las culturas indígenas del pasado. La reivindicación del "indio muerto" forma parte de un pasado glorioso cuyos vestigios están a la vista en los numerosos sitios arqueológicos que se extienden en toda la región mesoamericana. Estos vestigios fueron un referente fundamental para la elaboración del discurso nacionalista en el siglo XX que tendría en la escuela y los museos, las instituciones más importantes para su difusión y la forja de la identidad nacional. La identidad mexicana promovida por el estado post-revolucionario a lo largo del siglo XX, haría referencia al mestizaje de la población, a partir de la fusión de razas y culturas indígenas y europeas que darían lugar a la creación de la "raza cósmica", heredera de la tradición precolombina y europea. La muestra de ello está en los libros de texto y la manera en que se integran la multiplicidad de sitios arqueológicos, museos y piezas que forman parte del patrimonio arqueológico, como elementos de la grandeza de "lo mexicano". A la par que se alimentaba el imaginario constitutivo de la Nación, los conocimientos del patrimonio arqueológico eran interpretados y difundidos por los arqueólogos a través del turismo, sobre todo del turismo nacional y educativo (Villalobos, 2014).

En el proceso de construcción cultural de la nación, las actividades dirigidas por el Estado para forjar patria, tienen en el pasado prehispánico su piedra de toque. Desde la segunda mitad del siglo XIX se crearon los instrumentos jurídicos para nacionalizar diversos bienes, antes en manos de la Iglesia católica o de particulares. Desde 1859, cuando se promulga la nacionalización de los bienes de las asociaciones religiosas, el gobierno de Benito Juárez expediría leyes para asegurar que dichos bienes quedaran en manos de la nación, lo cual fue seguido por un conjunto de normas que buscaban la preservación y conservación del patrimonio nacional (Pérez, 2017), que se integraría como parte de un discurso nacionalista para lograr la cohesión social interna y la distinguibilidad externa. Durante ese periodo, también fueron expropiadas muchas de las tierras comunales que detentaban los indígenas. La nacionalización de los bienes de la iglesia se inscribe dentro de una larga historia por la búsqueda de referentes culturales, con el propósito de unificar a la nación y fortalecer la identidad nacional. Esta lucha se remonta a "los intentos de los criollos del siglo XVIII por crear una identidad propia, diferenciada de la metrópolis colonial" (Cottom, 2008: 62).

Desde mediados del siglo XIX, los sitios arqueológicos formaron parte del patrimonio cultural mexicano, mediante el cual la naciente nación mexicana buscaba distinguirse del conjunto de naciones y asegurar su independencia. Estos vestigios fueron integrados como símbolos a los que se hacía referencia al hablar de la grandeza del pasado prehispánico de la nación mexicana. Junto con ello aparecen las guías turísticas que proporcionan información a los visitantes nacionales y extranjeros. Se hace mención explícita a los sitios arqueológicos de Teotihuacán, Tula, Casas Grandes, Xochicalco, Tepoztlán, Cholula, Mitla, Palenque y Chichén Itzá, entre otros, como lugares dignos de ser visitados (Riedel 1892, citado por Villalobos, 2014). Dichos sitios arqueológicos y las piezas que de ellos se extrajeron para integrarlos a los museos, conformaron un patrimonio cultural cuya valorización ha estado íntimamente ligada al surgimiento y consolidación de un discurso nacionalista que buscaba distanciarse del pasado colonial novohispano.

Ya en el siglo XX, los procesos de patrimonialización de zonas arqueológicas y monumentos históricos, estarían acompañados de la creación y promoción de una amplia gama de prácticas culturales, tales como las danzas y música regionales, cuya difusión y enseñanza estaría a cargo de la Secretaría de Educación Pública, la cual tenía a su cargo la educación pública, gratuita y obligatoria.

El aprendizaje del pasado pre-colombino impartido en la escuela, tendrían en el turismo educativo un espacio institucional para su realización. Las visitas de los niños a las zonas arqueológicas y a los museos, estarían acompañadas de relatos e ilustraciones en los libros de texto gratuitos contemplados en los programas de educación básica. Además, ya desde la década de 1930 los turistas nacionales y extranjeros eran invitados a visitar Pátzcuaro, Michoacán, incentivados por la puesta en funcionamiento del ferrocarril, para apreciar el paisaje, la comida y las danzas de la región. Dos años más tarde, en 1932, se llevó a cabo el "Homenaje Racial" para conmemorar los 400 años de la fundación de la ciudad de Oaxaca. En esa ocasión se representó por vez primera la "Guelaguetza", un festival dancístico y musical en el cual se pretende representar a las siete regiones que integran al estado. El festival fue promovido por el gobierno del estado de Oaxaca, encabezado por Plácido Zárate y desde entonces es la festividad principal que reúne la música, danza y gastronomía de Oaxaca. Aunque no todos los danzantes que participan son indígenas, la Guelaguetza se publicita como una manifestación "indígena autóctona" en 
la cual se recogen las "más añejas" tradiciones del estado de Oaxaca. Para los historiadores, esta fiesta "no es más que un artificio para atraer al turismo" (Lira, 2014: 75).

En 1952 se funda el Ballet Folklórico de México dirigido por Amalia Hernández, cuyas danzas regionales siguen siendo uno de los principales atractivos turísticos que desde entonces se escenifican en el Palacio de Bellas Artes, en la Ciudad de México. Con esa misma dinámica, se dan a conocer diversas danzas, como la "Danza de los Viejitos" creada en la década de 1960 en la isla de Jarácuaro, la cual muy pronto se convierte en un ícono de lo Michoacano (Martínez, 2016). La danza "Flor de Piña" es creada en la década de 1950 y se presenta como una danza que representa a la región de Tuxtepec en la Guelaguetza.

A las festividades de música y danza antes señaladas, se sumó la revaloración de las manufacturas del "arte popular". Desde 1921 se realizaban exposiciones de las artes populares de México que posteriormente serían exportadas y exhibidas con el propósito de promover su venta y atraer al turismo estadounidense (Martínez, 2016).

Durante el siglo XX, la creación del Instituto Nacional de Antropología e Historia en 1939, el Instituto Nacional de Bellas Artes en 1947, y el Instituto Nacional Indigenista en 1948, mantendría y fortalecerían el entramado institucional con el propósito de mantener y gestionar el patrimonio nacional en manos el estado. Al paso de las décadas iría conformando también una legislación tendiente a garantizar la salvaguardia, protección y la propiedad del patrimonio de la nación sobre monumentos, bienes arqueológicos e históricos entre otras cosas (Pérez, 2017).

Otras expresiones culturales fueron re-significadas en función del mercado turístico. Este es el caso de la danza de los "voladores", cuyo origen se remonta al periodo prehispánico, la cual se practicaba por totonacas, nahuas, huastecos y otros grupos de México, así como por quichés, kaqchiqueles, achi de Guatemala y Nicaragua (López de Llano, 2016). Los voladores de la región de Papantla se popularizaron en ferias culturales de México y del extranjero, convirtiéndose en una de las actividades económicas más importantes generadoras de ingresos económicos de la región de Papantla, Veracruz. Los danzantes, además de participar como voladores se desempeñan como jornaleros, albañiles, comerciantes o artesanos. Participan en ferias y festivales regionales, como Cumbre Tajín, iniciada en el año 2000 en el Parque Temático Takilhsukut, en Papantla, Veracruz (Zúñiga, 2016) o en el extranjero, como en el Indian Summer Festival de Estados Unidos y el White Nights Festival, en Rusia (López de Llano, 2016). Los voladores de Papantla también se exhiben de manera permanente en las zonas arqueológicas de El Tajín y Tulum, y en el teatro del centro vacacional de X'caret, en la Riviera Maya, así como en el bosque de Chapultepec junto al Museo Nacional de Antropología en la Ciudad de México.

\section{Turismo, patrimonio y pueblos indígenas en México}

México cuenta con un amplio, diverso y rico patrimonio cultural, cuyo reconocimiento ha articulado dos grandes tendencias: por un lado, la que apuesta al fortalecimiento y promoción de la identidad nacional y, por otro, que promueve el desarrollo turístico como una manera de atraer recursos, en lo cual también participan pueblos y comunidades, sea a través de la venta de sus artesanías, la exhibición de sus danzas. Así las cosas, no existe una oposición entre los usos educativos e identitarios del patrimonio cultural, de aquél que se destina para el ocio, el espectáculo y el turismo.

Para 2017, el país contaba con 34 lugares designados por la UNESCO como patrimonio de la humanidad. De estos, 27 eran reconocidos como "bien cultural", seis como "bien natural" y uno como "bien mixto". Esto lo convirtió en el séptimo país con mayor cantidad de sitios inscritos en la lista de bienes patrimonio de la humanidad, sólo por detrás de Italia, China, España, Francia, Alemania, e India; así como primero en América Latina y Caribe, y también en el continente americano. Además de estos sitios de "patrimonio material tangible", contaba con ocho tradiciones y festejos, considerados como "bienes inmateriales o intangibles".

Los objetos de la cultura material del pasado prehispánico (trátese de monumentos arqueológicos, vasijas, arte rupestre) y de lo que se conoce como patrimonio intangible (prácticas culturales específicas, como las danzas, la cocina, la música) fueron incorporados como elementos de su patrimonio cultural, entendido por ello, la herencia de un pueblo o una sociedad.

Junto con los sitios y prácticas reconocidos por la UNESCO como "Patrimonio de la Humanidad", el gobierno federal mexicano lleva a cabo una política tendiente a favorecer el desarrollo turístico del país más allá de los sitios de turismo de "sol y playa". Para ello, desde 2001 puso en marcha el Programa de Pueblos Mágicos (PPM), por medio del cual se busca atraer al turismo mediante la patrimonialización de aquellos pueblos que por sus expresiones culturales, sus monumentos, zonas arqueológicas o por los 
recursos naturales que albergan, son dignos de ser visitados. Para 2014, se contaba con 83 localidades reconocidas como "pueblos mágicos" y en 2017 ya sumaban 121. El PPM forma parte de la promoción del turismo cultural, por medio de la cual se diversifica la oferta turística, aunque hasta hoy el turismo de "sol y playa" sigue siendo la principal fuente de divisas que ingresan al país por la actividad turística.

Bajo la misma perspectiva, la Comisión Nacional para el Desarrollo de los Pueblos Indígenas (CDI), dependencia del gobierno federal para orientar la política pública dirigida a la población indígena, impulsó el Programa de Turismo Alternativo en Zonas Indígenas, con proyectos turísticos en 23 entidades federativas creados con el propósito de promover el desarrollo local (CDI, 2018). Además, en algunos estados de la República Mexicana se han promovido programas similares al PPM. Es el caso, por ejemplo, el programa de "Pueblos con Encanto" que lleva a cabo el Estado de México. En épocas más recientes, se puso en marcha el Programa "Paraísos Indígenas" el cual invita a los turistas a vivir experiencias inolvidables y a sentir la energía de las montañas, vivir la aventura, disfrutar de las cascadas, conectarse con la naturaleza y con las culturas indígenas, promovido por la Comisión Nacional para el Desarrollo de los Pueblos Indígenas (CDI), una dependencia del gobierno federal creada para promover el desarrollo de los pueblos indígenas de México. Dicho programa busca promover sitios turísticos con alto valor natural, cultural e histórico y se plantea un esquema participativo, coordinado de entre empresarios indígenas y el gobierno federal. Para 2016, se contaba con 105 sitios de turismo alternativo promovidos por el programa "paraísos indígenas" (CDI 2018). Todo lo anterior muestra que el patrimonio cultural constituye un recurso susceptible de ser reconocido globalmente y explotado con fines turísticos, y como un recurso para promover el desarrollo económico y la generación de divisas.

No obstante la recuperación de las expresiones culturales de los pueblos indígenas para la promoción turística, a lo largo del siglo XX la política del estado se orientó a desindianizar a México a través de la acción de diversas instituciones, entre ellas la educativa. Fue hasta 1992, después de una serie de luchas emprendidas por las organizaciones indígenas por lograr su reconocimiento, cuando finalmente se reconoce constitucionalmente la naturaleza pluricultural de la nación. En ella se establece que el Estado protegerá las lenguas, culturas, tradiciones, usos, costumbres de los pueblos indígenas. No obstante los avances, hasta la fecha no se reconocen los derechos políticos de los pueblos indígenas al territorio y la gestión autónoma. Por el contrario, en ese mismo año, 1992, se da por terminado el reparto agrario y se realiza una reforma constitucional que permite que las tierras ejidales y comunales, en manos de los campesinos e indígenas, puedan ser vendidas, hipotecadas o enajenadas. Con ello se abre al mercado la venta de tierras y se intensifica un proceso de acumulación por despojo. Diversas organizaciones perderían sus tierras, y se verían afectadas por la invasión de empresas mineras, energéticas y por grandes emprendimientos turísticos llevados a cabo por las cadenas globales de valor. Y si bien en 2001 se aprueba una nueva reforma constitucional de reconocimiento a los derechos colectivos de los pueblos indígenas, los temas centrales relacionados con la protección y defensa de su territorio, de sus recursos naturales, de sus tierras de cultivo, nuevamente quedan fuera.

\section{Patrimonio, turismo y pueblos indígenas: el caso de Chile}

Al igual que los otros estados nacionales latinoamericanos, Chile se independiza a principios del siglo XIX. Los intelectuales y clase política buscan instaurar un proyecto unitario, donde pareciera no existir diversidad cultural (Pinto, 2003). Salvo algunos resabios que enarbolan al indígena, en especial a los mapuches con el pueblo "guerrero", el interés nacional no se fundamenta en esto, más bien busca una unidad territorial y cultural basada en la cultura europea, que se verá profundizada con los procesos de colonización, invisibilizando y negando la diversidad de los pueblos indígenas. Las políticas orientadas a la población indígena serán de asimilación cultural y despojo de sus territorios históricos.

La construcción del patrimonio cultural nacional en Chile se inicia con la integración de diversas colecciones de artefactos culturales (textiles, piezas arqueológicas), proceso que se había iniciado en forma espontánea por misioneros, exploradores y coleccionistas particulares. Este proceso se da junto con la fundación de museos nacionales y la creación de museos regionales (Alvarado, 2016). No obstante, las colecciones pasan a manos privadas y no será sino hasta más adelante cuando se integren como parte del patrimonio cultural de la nación. No se identifica claramente una relación entre el proceso de construcción de la identidad nacional chilena con el desarrollo del turismo, aunque estos territorios incorporados como la Araucanía (territorio en el centro sur de Chile habitado por el pueblo mapuche) y los del norte comienzan a habitarse y chilenizarse, abriéndose como nuevos destinos para habitar y potencialmente para visitar.

Las identidades étnicas se vinculan a los procesos de modernización y de la conformación de las fronteras nacionales. En el norte, luego de la Guerra del Pacífico (1897-1883), las tierras incorporadas a Chile 
estarán habitadas por poblaciones indígenas de origen andino, principalmente de origen aymara, quechua y atacameña quienes comparten una extensa área (hoy parte del sur boliviano, noroeste argentino y norte chileno), territorio donde se impulsarán políticas de chilenización (González, 2002). Mientras en el sur de Chile, la población Mapuche sufrirá el despojo de su territorio, con la ocupación militar llamada "Pacificación de la Araucanía", siendo distribuidas sus tierras mayoritariamente a colonos nacionales y extranjeros.

No obstante este tipo de colonización segregacionista, el pasado indígena aparece en algunos textos fundacionales. La obra de José Toribio Medina titulada "Los aboríjenes de Chile", muestra un esfuerzo por reconstruir el mundo indígena precolombino a partir de una serie de artefactos arqueológicos y etnográficos. Con ello, los territorios chilenos dejan de ser vistos como terrenos baldíos, a pesar que las leyes de colonización así lo declaran. Otros autores, como Richard Latcham, recuperan el trabajo de Medina, para referirse al pasado precolombino. No obstante estos esfuerzos, fue hasta finales del siglo XX cuando las colecciones de vestigios arqueológicos ingresaron al campo de las consideraciones artísticas y es, hasta la década de 1980, cuando se inaugura de manera independiente el Museo Chileno de Arte Precolombino y la Galería de Arte Precolombino Nacional (más tarde conocida como Museo Arqueológico de Santiago). Estos proyectos surgen del interés de los coleccionistas privados e intelectuales progresistas. Fue a partir de entonces que se fue conformando un nuevo campo, en el que participan arqueólogos, coleccionistas, antropólogos, historiadores, conservadores artistas y escritores, bajo una perspectiva vinculada a la apreciación del arte precolombino.

Especialmente en el norte de Chile, el patrimonio arqueológico es clave en la construcción de la identidad regional y turística. Diversos autores han advertido la relevancia del turismo como un tema vinculado a la movilidad y redes sociales especialmente en el área de San Pedro de Atacama (Gundermann \& González, 2008), destacado atractivo turístico, y también la importancia que ha adquirido el turismo como parte definitoria de la propia cultura del pueblo atacamaño o likanantay (Anta, 2007). Otros investigadores analizan en forma crítica el desarrollo del turismo vinculado al rol de los arqueólogos y su patrimonialización. En esta línea, estudios como los de Cárdenas (Cárdenas, 1999) y Ayala (Ayala, 2007, 2008) plantean un análisis sobre el papel que juegan los actores externos al proceso de valorización y promoción turística de los lugares considerados de valor arqueológico y turístico en desmedro de los pueblos originarios. Estos estudios cuestionan el desarrollo turístico, considerándolo como una de las formas de dominación que impone el conocimiento científico (arqueológico) y las políticas estatales sobre lo que se ofrece, lo que se estudia y, finalmente, lo que se valoriza como un producto turístico, con escasa participación de los pueblos originarios. Mientras en el centro sur, el patrimonio cultural intangible indígena progresivamente pasa a ser clave en el desarrollo turístico e identidad regional sólo a partir de 1990.

Por otro lado, muchas de las poblaciones indígenas se consideraron desde el Estado como desaparecidas. Es así que los elementos culturales que les pertenecían, tanto materiales como inmateriales, pasaron a formar parte del acervo regional mestizo - nacional (Campos 2016). Esto es, fueron absorbidos por la identidad nacional envolvente, que incorporó como propio el patrimonio cultural, que dejó de ser considerado como indígena.

Después de la dictadura (1973-1990) y con el proceso de democratización, hay un resurgimiento étnico de pueblos que se habían dado por desaparecidos o que no se les reconocía derechos especiales, los cuales entran a disputar el patrimonio cultural indígena con el nacional. Incluso, las organizaciones indígenas entran a disputar en la arena internacional, como cuando esos recursos han sido ya catalogados como patrimonio de la humanidad y su control es escindido o expropiado a las propias comunidades que los conservaban.

Campos (2016) plantea como ejemplo el nguillatun (ceremonia religiosa mapuche) como potencial patrimonio de la humanidad, que por un lado representa un reconocimiento pero, por otro lado, sigue siendo una apropiación indebida por agentes que no representan ni comprenden a cabalidad la complejidad de la vida ceremonial del pueblo mapuche. Lo mismo acontece con la herbolaria y el uso de plantas medicinas mapuche, como son los productos de la farmacopea, sin considerar el papel que juega la machi y otros especialistas en el proceso de curación (Campos, 2016). Desde los años 1990, con el retorno a la democracia, las organizaciones indígenas comenzaron a reclamar su participación en la formulación de las políticas de manejo de las colecciones y bienes arqueológicos.

Actualmente, Chile cuenta con cinco lugares declarados por la UNESCO como patrimonio de la humanidad. Estos son: Oficinas Salitreras Humberstone y Santa Laura, Valparaíso, Campamento Sewell, Iglesias de Chiloé y Parque Nacional Rapa Nui. A través de esta declaración, el estado chileno se apoya para promover la visita del turismo internacional y difundir el conocimiento sobre su patrimonio cultural. Sólo uno de ellos está asociado directamente a un pueblo indígena que es el Parque Nacional Rapa Nui, que desde 2017, luego de años de demandas y reivindicaciones indígenas, fue traspasada su administración a una comunidad Rapa Nui. 


\section{Pueblos indígenas y desarrollo del turismo en Chile}

A diferencia de México, el desarrollo del turismo en territorios indígenas se va a conformar asociado a atractivos naturales, que en algunos casos como el norte de Chile se vinculan a patrimonio arqueológico. Sólo a partir de la década de 1990 se impulsará desde instituciones públicas y ONGs en forma más sistemática el turismo asociado a las comunidades indígenas en el marco de políticas indígenas, el cual se denomina turismo indígena o turismo mapuche para el caso de la Región de la Araucanía.

Desde 1990 el estado chileno post-dictadura lleva a cabo una política indígena mediante la cual busca dar visibilidad a las poblaciones indígenas, e incorporarlas al desarrollo regional.

A través de la promulgación de la Ley Indígena, se reconoce oficialmente la existencia de los nueve pueblos originarios (originalmente en 1993 se reconocen ocho: aymara, quechua, atacamaño, coya, mapuche, rapanui, kaweskar, yagan, posteriormente en 2006 se incorpora a los diaguitas) en el territorio chileno, utilizando el concepto de "etnias". Sólo se incorpora en el discurso público el concepto de pueblos indígenas u originarios años después y en especial con la ratificación del Convenio 169 de la OIT en 2008.

La ley indígena tiene por tema central generar políticas especiales para los pueblos indígenas. Estas políticas serán impulsadas por la Corporación Nacional de Desarrollo Indígena (CONADI). También se reconoce la "calidad indígena", la "comunidad indígena" y la "asociación indígena" quienes serán los sujetos reconocidos de la política pública, como también define Áreas de Desarrollo Indígena (ADI) (Gobierno de Chile, 1993). Un año más tarde se aprueba la Ley de Medio Ambiente, la cual incorpora el tema de la participación social y define los recursos arqueológicos, paisajísticos y turísticos como parte del patrimonio ambiental. Ambas leyes forman parte de los compromisos de los gobiernos democráticos post-dictadura, también conocidos como "gobiernos de la Concertación" que arribaron al poder después de la dictadura de Pinochet (1973-1989).

A la par que se da el reconocimiento de los pueblos indígenas, el turismo comienza a tener cada vez más importancia asociado a los territorios indígenas históricos. El turismo ha sido visto como una manera de promover el desarrollo y generar empleos en diversos sectores, entre ellos, los indígenas. Desde el año 2003, esto se hace más visible cuando se plantea al turismo indígena como una fuente de desarrollo para los pueblos indígenas (Orígenes, 2003).

De la Maza $(2016,2017)$ ha mostrado que el turismo que se desarrolla en los territorios indígenas, tiene por característica incorporar los elementos étnicos en un imaginario que tiende a asociar "lo indígena" con la naturaleza o como un bien cultural del pasado, que se mantiene, en especial en el norte de Chile, mientras en otros espacios, como en la zona mapuche, se promueve un turismo cultural indígena. La oferta turística, por tanto, tiene la particularidad de promover el turismo indígena como parte de un acercamiento con la naturaleza, en especial en áreas donde predominan parques nacionales o el principal atractivo es la naturaleza y el paisaje. A este imaginario también responden los intereses de las propias organizaciones indígenas del país, que se reclaman protectoras y custodias de los bosques, ríos y lagos, desde tiempos inmemoriales. Esto se evidencia cuando entran en conflicto con proyectos extractivistas que amenazan sus territorios, por ejemplo con la minería en el norte de Chile o centrales hidroeléctricas en territorio mapuche.

La turistificación en las regiones indígenas coincide con otras actividades llevadas a cabo en el medio rural. En los últimos años, desde el Instituto de Desarrollo Agropecuario (INDAP), dependiente del Ministerio de Agricultura, se han incluido en sus programas el desarrollo del turismo en zonas rurales como una alternativa de agro-negocios para la agricultura familiar campesina (Schaerer y Dirven, 2001), el cual ha contado con el apoyo de otros organismos públicos y privados.

En este mismo contexto, las organizaciones indígenas han ido integrando al turismo como una fuente de ingresos. De la Maza (2017) analiza la comuna de San Pedro de Atacama, en el norte, la cual cuenta con una importante trayectoria de desarrollo turístico asociada al paisaje, parques nacionales, patrimonio arqueológico y la cultura atacameña (o likan antay). Mientras en la región de la Araucanía, se ha promovido desde la institucionalidad pública un turismo asociado a la cultura mapuche. Este territorio no ha estado ajenos a la demanda de reconocimiento y reivindicaciones históricas, territoriales y culturales del pueblo mapuche, el cual ha visibilizado el "conflicto mapuche" a nivel público, pero a su vez se promociona un turismo cultural indígena y armónico con la naturaleza.

El desarrollo turístico ha permitido a las organizaciones indígenas contar con una plataforma para disputar el control de sus territorios frente a otros actores e intereses, sin estar exentos de dificultades, entre ellos la apropiación de íconos culturales indígenas por empresas o actores turísticos no indígenas. Con ello, el turismo mapuche, llamado también turismo indígena y comunitario por algunos autores, ha adquirido en algunos lugares “... las proporciones de un relato mágico cuya realización solucionará los 
problemas que sobreabundan en las comunidades indígenas y rurales, que ven en sus costumbres y en el bien paisajístico el medio último para integrarse a la modernidad" (Piquilman y Skewes, 2009: 170).

Los pueblos originarios son, en este sentido, sujetos de un proceso de identidad hetero-dirigida, determinada por el turismo empresarial, cuya imagen se encasilla dentro de categorías sociales conocidas (como pueblos tradicionales o pre-modernos), lo cual entraña una forma de colonialismo que vuelve a colocar, una vez más, a los no-indígenas en un estatus de superioridad. Pero por otro, como un espacio de afirmación identitaria indígena que reclama sus derechos al control territorial y cultural en el contexto del desarrollo turístico.

\section{Reflexiones finales}

A lo largo del siglo XX, el nacionalismo mexicano asumiría como una de sus raíces, la existencia de un pasado indígena glorioso, cuya historia está anclada en un pasado inmemorial. La nación se construye culturalmente como una colectividad mestiza, producto de la fusión de razas y culturas. En México, se reconoce la naturaleza pluricultural de la nación luego de una larga política indigenista, plasmada en la constitución de 1992 y reformulada en el 2001. Sin embargo, estas reformas quedan a nivel declarativo cuando se observa el despojo del que son objeto ante el avance de la minería, de los macro-proyectos energéticos y/o las inversiones en los grandes centros de desarrollo turístico.

En Chile los indígenas no aparecen de manera explícita en el discurso constitutivo de la nación, sino hasta finales de la década de 1980. No hay en el imaginario nacionalista chileno un régimen de alteridad que le permita a la nación chilena identificar a los pueblos originarios como raíz de su cultura. Será hasta la caída del régimen de Pinochet, como parte el proceso de democratización, que se incorpora a la población indígena dentro de una nueva idea de nación, pero que no se plasma en un reconocimiento constitucional ni en derechos políticos, sino más bien en una valoración cultural. Dicho reconocimiento parte de las demandas de un movimiento indígena que se expresa a lo largo del país.

A pesar de las diferencias históricas en cuanto a su relación con la presencia indígena como elemento constitutivo de la nación, el siglo XXI se inaugura con discursos sobre la multiculturalidad y el reconocimiento a los derechos culturales de los pueblos indígenas en América Latina. Junto con estos reconocimientos hay ciertas concesiones, a cuentagotas, a las demandas indígenas, producto del movimiento social que se había venido gestando desde la década de 1970 en diversos países latinoamericanos. En términos generales, este reconocimiento se da a la par en que el capital (inmobiliario, turístico, minero, energético) avanza sobre las tierras y los territorios indígenas, sea por medio de la privatización, el otorgamiento de concesiones a empresas mineras y energéticas, o bien, a las grandes empresas turísticas multinacionales. Es en ese contexto en el que la turistificación de comunidades y regiones indígenas se presenta como una política pública, con el objetivo de favorecer procesos de desarrollo que tienen un alcance muy limitado en las comunidades. Dependiendo de cada experiencia, el desarrollo de proyectos de "turismo alternativo" en las regiones indígenas depende de la capacidad de agencia de las comunidades y del tipo de apoyos que logren obtener por parte de los gobiernos locales o del gobierno federal, así como de asociaciones de la sociedad civil.

El proceso de turistificación y la participación de las comunidades, no escapa del enfoque del mercado que busca integrar la diferencia cultural a través de la folclorización de las expresiones culturales indígenas, algunas de las cuales son reconocidas por la UNESCO como "patrimonio cultural intangible" de la humanidad. Dichos reconocimientos tienden a atraer a un mayor número de turistas gracias a la promoción que realizan los tour-operadores, que dan a conocer los rituales, danzas y ceremonias indígenas como patrimonio de la humanidad. Se trata de un reconocimiento turistificado de la diversidad cultural: una versión espectacularizada del "indio permitido" (Hale, 2004) ofrecida a los turistas, lo cual contrasta con las prácticas y la relación de exclusión, precariedad y violación a los derechos humanos que afecta a la población indígena. Por otra parte, se trata de políticas públicas que tiende a favorecer la creación de un "empresariado indígena", como lo expresan los programas promocionales de la CDI, lo que significa se apoyan proyectos de reducido impacto económico y social, en beneficio de algunos grupos y familias de las comunidades que, con el apoyo del gobierno, tenderían a capitalizar las inversiones y a diferenciarse del resto de la comunidad.

Un elemento clave que no hay que olvidar a la hora de analizar el desarrollo del turismo en México, es la vecindad con Estados Unidos, de donde proviene la mayoría de los turistas extranjeros. En Chile, en cambio, el turismo rural o indígena es más doméstico y opera como complemento de las actividades económicas campesinas, lo cual tiene implicaciones en las formas de integración al mercado.

El desarrollo del gran turismo en México favorece a grandes empresas transnacionales, que son las beneficiarias de la expropiación de tierras y recursos naturales de los ejidos y comunidades indígenas. 
Tanto en zonas de montaña como en la Sierra Tarahumara en Chihuahua, o en las zonas costeras en la Riviera Maya, las empresas españolas y estadounidenses son las principales beneficiarias de la re-territorialización del capital turístico y del despojo a las comunidades indígenas. Estos son algunos casos que muestran que el proceso de producción turística en México es más globalizado y polarizante que en Chile. En este último país hay un proyecto integrador neoliberal, pero integrador al fin. En México, la agencia mexicana de relación con los pueblos indígenas, la CDI, promueve el "turismo alternativo" y los "paraísos indígenas" pero con muy pocos recursos, sin que haya seguimiento y un balance acerca de su funcionamiento. La política pública vinculada con el turismo la realiza el Fondo Nacional de Turismo (Fonatur), que opera como una super-secretaría que funciona tanto para la compra de tierras y la promoción de inversiones de capital nacional y extranjero, lo cual realiza muchas veces sin aplicar los criterios de consulta previa e informada que previenen la Declaración Mundial sobre Derechos y Cultura Indígena de la ONU y el Convenio 169 de la Organización Internacional del Trabajo, cuando los territorios indígenas son afectados por la expansión del gran turismo y de la industria inmobiliaria.

\section{Agradecimientos}

Este artículo se escribió gracias al apoyo de la Universidad Nacional Autónoma de México, proyecto PAPIIT IN301117, "Patrimonio cultural, turismo y pueblos indígenas: un estudio de etnografía comparada"; al apoyo del Centro de Estudios Interculturales e Indígenas-CIIR: CONICYT/FONDAP/15110006; al Proyecto FONDECYT REGULAR N ${ }^{\circ} 1170236$.

\section{Bibliografia}

Alvarado, M.

2016. "Arte textil mapuche y patrimonio. Vestigios y actualidad" en, Alvarado, M., L. Campos y otros, Patrimonio y pueblos indígenas. Reflexiones desde una perspectiva interdisciplinaria e intercultural. Santiago de Chile: Pehuén Editores S.A.

Anta, J.

2007. Desarrollo y turismo en Atacama (Chile). De la precariedad a la necesidad. In D. Lagunas (Ed.), Antropología y turismo (pp. 153-163). México: Universidad Autónoma del Estado de Hidalgo/Plaza y Valdés.

Ayala, P.

2007. Relaciones entre atacameños, arqueólogos y Estado en Atacama (norte de Chile). Estudios Atacameños(33).

Ayala, P.

2008. Políticas del pasado: Indígenas, arqueólogos y estado en Atacama. Chile: Universidad Católica del Norte-IIAM.

Campos, L.

2016. "El patrimonio y las demandas de reconocimiento cultural" en, Alvarado, M., Campos, L. y otros, Patrimonio y pueblos indigenas. Reflexiones desde una perspectiva interdisciplinaria e intercultural, CIIR - Pehuén, Santiago de Chile.

Cárdenas, U.

1999. Percepciones de las comunidades atacameñas sobre el tratamiento del patrimonio cultural de la zona. Retrieved from http://www.mendeley.com/research/percepciones-las-comunidades-atacameñasCDI -sobre-su-patrimonio-cultural/\#page-1

2018. Programa Turismo Alternativo para Zonas Indígenas, Comisión Nacional para el Desarrollo de los Pueblos Indígenas, http://www.cdi.gob.mx/focalizada/ptazi/index.php Consultado el 30 de abril de 2018. Comaroff, J. y Comaroff, J.

2011. Etnicidad, S.A., Katz ediciones, Buenos Aires.

Cottom, B.

2008. Nación, patrimonio cultural y legislación: los debates parlamentarios y la construcción del marco jurídico federal sobre monumentos en México, siglo XX, Ed. Porrúa, México.

De la Maza, F.

2015. "State Conceptions of Indigenous Tourism in Chile", Annals of Tourism Research, 56: 80-95. 
Coronado, Gabriela

2008. "Insurgencia y turismo. Reflexiones sobre el impacto del turista politizado en Chiapas" en, Pasos. Revista de Turismo y Patrimonio Cultural, Vol. 6 (1): 53-68.

De la Maza, F.

2017. Tourism in Chile's indigenous territories: the impact of public policies and tourism value of indigenpus culture. Latin American and Caribbean Ethnic Studies, 13(1): 94-111.

Flores, G. y Nava, F., (comp.)

2016. Identidades en venta. Músicas tradicionales y turismo en México. Instituto de Investigaciones sociales, UNAM.

Flores, G.

2017. La Pirekua como Patrimonio Cultural Inmaterial de la Humanidad, Instituto de Investigaciones Sociales de la UNAM.

Frigolé, J.

2012. "Cosmologías, patrimonialización y eco-símbolos en el Pirineo Catalán en un contexto global", Revista de Antropología Social 21: 173-196

Giménez, G.

2000. "Identidades étnicas. Estado de la cuestión", en Los retos de la etnicidad en los estados - nación del siglo XXI, México, INI - CIESAS - Miguel Ángel Porrúa, p. 45-70

Gobierno de Chile

1993. Ley Indigena 19.253. Chile.

González, S.

2002. Chilenizando a Tunupa. La esceula pública en el Tarapacá andino 1880-1990.: Dirección de Bibliotecas, Archivos y Museos.

Graburn, N., \& Barthel-Bouchier, D.

2001. Relocating the tourist. International Sociology, 16(2): 147-158.

Grünewald, R. d. A.

2006. Tourism and ethnicity. Horizontes antropológicos, vol. 1.

Gundermann, H., \& González, H.

2008. Pautas de integración regional, migración, movilidad y redes sociales en los pueblos indígenas de Chile. Universum (Talca), 23(1).

Hale, C.

2002. Does Multiculturalism Menace? Governance, CUltural Rights and the Politicis of Identity in Guatemala. Journal of Latin American Studies(34).

Hale, C.

2004. "Rethinking Indigenous Politics in the Era of the "Indio Permitido". NACLA Reportingof the Americas, Vol. 38, 2, 2004, http://www.tandfonline.com/doi/abs/10.1080/10714839.2004.11724509, p 16 - 21 consultado el 23 de agosto de 2017.

Heinich, Nathalie

2015. La fabrique du patrimoine. "De la cathedrale à la pètite cuillere". Editions de la Maison des scienses de l'homme.

Hernández, J. J.

2009. “Tequila: centro mágico, pueblo tradicional. ¿Patrimonialización o privatización?”, en Andamios, Revista de Investigación Social, Universidad Autónoma de la Ciudad de México, 6 (12): 41-67.

Lagunas, D. (Ed.)

2007. Antropología y Turismo. México: Plza y Valdés-Universidad Autónoma del Estado de Hidalgo.

Lira, C.

2014. "El discurso patrimonial: una coartada para frenar el desarrollo de la ciudad de Oaxaca", Urbano, 17 (29): $72-87$.

López del Llano, $\mathrm{H}$.

2016. "Impacto del advenimiento turístico en la práctica músico - dancística del palo volador. El caso de la expresión del Totonacapan veracruzano de la costa", en Flores, G., y Nava F., (comp.) 2016, Identidades en venta. Músicas tradicionales y turismo en México. IIS UNAM, p 69-102.

López, A., y Marín G.

2010. "Turismo, capitalismo y producción de lo exótico. Una perspectiva crítica para el estudio de la mercantilización del espacio y la cultura” en, Relaciones 23 (31): 219-258.

MacCannell, D.

2003. El turista. Una nueva teoría de la clase ociosa. Barcelona: Editorial Melusina. 
Martínez, J. A.

2016. "Bailar para el turismo. La 'Danza de los viejitos' de Jarácuaro como artesanía", en en Flores, G., y Nava F. (comp.) 2016, Identidades en venta. Músicas tradicionales y turismo en México. IIS UNAM. p 69-102.

Michaud, M. P. e. J.

2001. Presentarion: tourisme et sociétés locales. Anthropologie et Sociétés, 25(2): 5-13.

Oehmichen, C.

2013. Enfoques antropológicos sobre el turismo contemporáneo. México: UNAM.

Orígenes, P.

2003. Turismo: una apuesta al Desarrollo de las Comunidades Indígenas de Chile: Programa Orígenes MIDEPLAN-BID.

Pereiro, X.

2015. Reflexión antropológica sobre el turismo indígena. Desacatos(47).

Pereiro, X.

2007. Los impactos del turismo en Kuna Yala (Panamá). Turismo y cultura entre los kuna de Panamá. 2007. Editorial Universitaria Ramón areces Fitur. Madrid.

Pérez R., M. L.

2017. “¿Cómo pasó? Reflexiones sobre la reconfiguración del campo cultural en México”, en Diario de Campo, 4 (1): 7-37.

Pinto, J.

2003. La formaicón del Estado y la nación, y el pueblo mapuche. De la inclusión a la exclusión. Santiago: DIBAM

Piquilman, M. Y Skewers, J.C.

2009 "Los paisajes locales y las encrucijadas del etnoturismo: reflexiones a partir de los proyectos turísticos de comunidades indígenas de la región de Los Lagos en Chile", Cuadernos de Turismo, 24: 169-191. Rojo, S. y Llanes, R.A.

2009. "Patrimonio y turismo: el caso el Programa Pueblos Mágicos", Topofilia, Revista de Arquitectura, Urbanismo y Ciencias Sociales. Centro de Estudios de America del Norte, El Colegio de Sonora, 1 (3). Santana, A.

2006. Antropología y turismo, ¿Nuevas bordas, viejas culturas? Barcelona: Editorial Ariel, S.A.

Schaerer, J. y Dirven, M.

2001. El turismo rural en Chile. Experiencias de agroturismo en las regiones del Maule, la Araucanía y Los Lagos, Red de Desarrollo Agropecuario, CEPAL, Santiago de Chile, 2001. UNW

2016. World Tourism Organization 2016, Estadisticas del turismo, en http://www.e-unwto.org/loi/ unwtotfb, consultado el 20 de mayo de 2017.

Villalobos, C.

2014. Arqueología mexicana en guías de turistas: educación y pasatiempo", en Anales de Antropología, Universidad Nacional Autónoma de México, 48 (2): 41-74.

Wang, $\mathrm{H}$.

2004. "Regulating Transnational Flows of People: An Institutional Analysis of Passports and Visa as a Regime of Mobility", en Identities: Global Studies in Culture and Power 11: 351-376.

Zamora, J. Y Barril M.E.

2007. "Turismo y vino. Un estudio formativo sobre la evolución de las rutas del vino en Chile" en, Estudios y Perspectivas en Turismo, 16: 173-194.

Zúñiga, F.

2016. Patrimonio cultural, etnicidad y turismo. Procesos de patrimonialización, turistificación y mercantilización en el Totonacapan veracruzano, tesis de doctorado en Antropología, Posgrado en Antropología de la UNAM, 2016

Recibido:

$15 / 12 / 2017$

Reenviado:

$07 / 05 / 2018$

Aceptado:

$08 / 05 / 2018$

Sometido a evaluación por pares anónimos 